\title{
Current Understanding of Multisystem Inflammatory Syndrome (MIS-C) Following COVID-19 and Its Distinction from Kawasaki Disease
}

\author{
Hulya Bukulmez ${ }^{1}$
}

Accepted: 22 May 2021 / Published online: 3 July 2021

(C) The Author(s), under exclusive licence to Springer Science+Business Media, LLC, part of Springer Nature 2021

\begin{abstract}
Purpose of Review In this article, I have reviewed current reports that explore differences and similarities between multisystem inflammatory syndrome in children (MIS-C) and other known multisystem inflammatory diseases seen in children, particularly Kawasaki disease.

Recent Findings Severe acute respiratory syndrome coronavirus 2 (SARS-CoV-2) is a human coronavirus causing the COVID19 disease which emerged in China in December 2019 and spread rapidly to the entire country and quickly to other countries. Currently, there is a pandemic of SARS-CoV-2 infection that results in $20 \%$ of patients admitted to hospital with illness, with $3 \%$ developing intractable acute respiratory distress syndrome (ARDS) with high mortality. However, pediatric COVID-19 is still reported to be a mild disease, affecting only $8 \%$ of children. Pathogenesis in children is comparable to adults. There are suggested impaired activation of IFN-alpha and IFN regulator 3, decreased cell response causing impaired viral defense, yet the clinical course is mild, and almost all children recover from the infection without major complications. Interestingly, there is a subset of patients that develop a late but marked immunogenic response to COVID-19 and develop MIS-C.

Summary Clinical features of MIS-C resemble certain pediatric rheumatologic diseases, such as Kawasaki disease (mucocutaneous lymph node syndrome) which affects small-medium vessels. Other features of MIS-C resemble those of macrophage activation syndrome (MAS). However, recent research suggests distinct clinical and laboratory differences between MIS-C, Kawasaki disease, and MAS. Since the start of the SARS-CoV-2 pandemic, MIS-C has become the candidate for the most common cause of acquired heart disease in children.
\end{abstract}

Keywords SARS-CoV2 $\cdot$ COVID-19 $\cdot$ MIS-C $\cdot$ Kawasaki $\cdot$ Macrophage activation syndrome (MAS)

\section{Introduction}

SARS-CoV-2 is a member of the coronavirus family which comprises a group of large non-segmented enveloped singlestranded RNA viruses, i.e., SARS-CoV (alpha) and MERS$\mathrm{CoV}$ (beta).

The SARS-Cov-2 infection seems to be linked with other coronaviruses despite differences in their epidemiology, pathology, and several of their structural proteins [1,2]. SARS$\mathrm{CoV}-2$, as the newest coronavirus infection and its immune

Hulya Bukulmez

hxb38@case.edu; hbukulmez@metrohealth.org

1 Department of Pediatrics, Division of Pediatric Rheumatology, Metro Health Medical Center, Case Western Reserve University, 2500 Metrohealth Drive, Cleveland, OH 44109, USA response profile, is currently being discovered. Investigators are using information about known coronaviruses to design urgent and effective therapies.

Some of the immune response to all coronavirus $(\mathrm{CoV})$ infections can be generalized and helpful in understanding the current SARS-CoV-2 infection and its complications [3] (Fig. 1):

- When an infection enters an organism, the innate immune and adaptive immune responses are initiated with first macrophage recognizing infection and presentation of $\mathrm{CoV}$ antigens to $\mathrm{T}$ cells [4]. This process leads to $\mathrm{T}$ cell activation and differentiation, including the production of cytokines associated with different $\mathrm{T}$ cell subsets [5], followed by the release of cytokines for immune response amplification. However, continued production of these mediators at massive levels due to viral persistence has a negative effect on $\mathrm{NK}$ and $\mathrm{CD} 8+\mathrm{T}$ cell activation. 


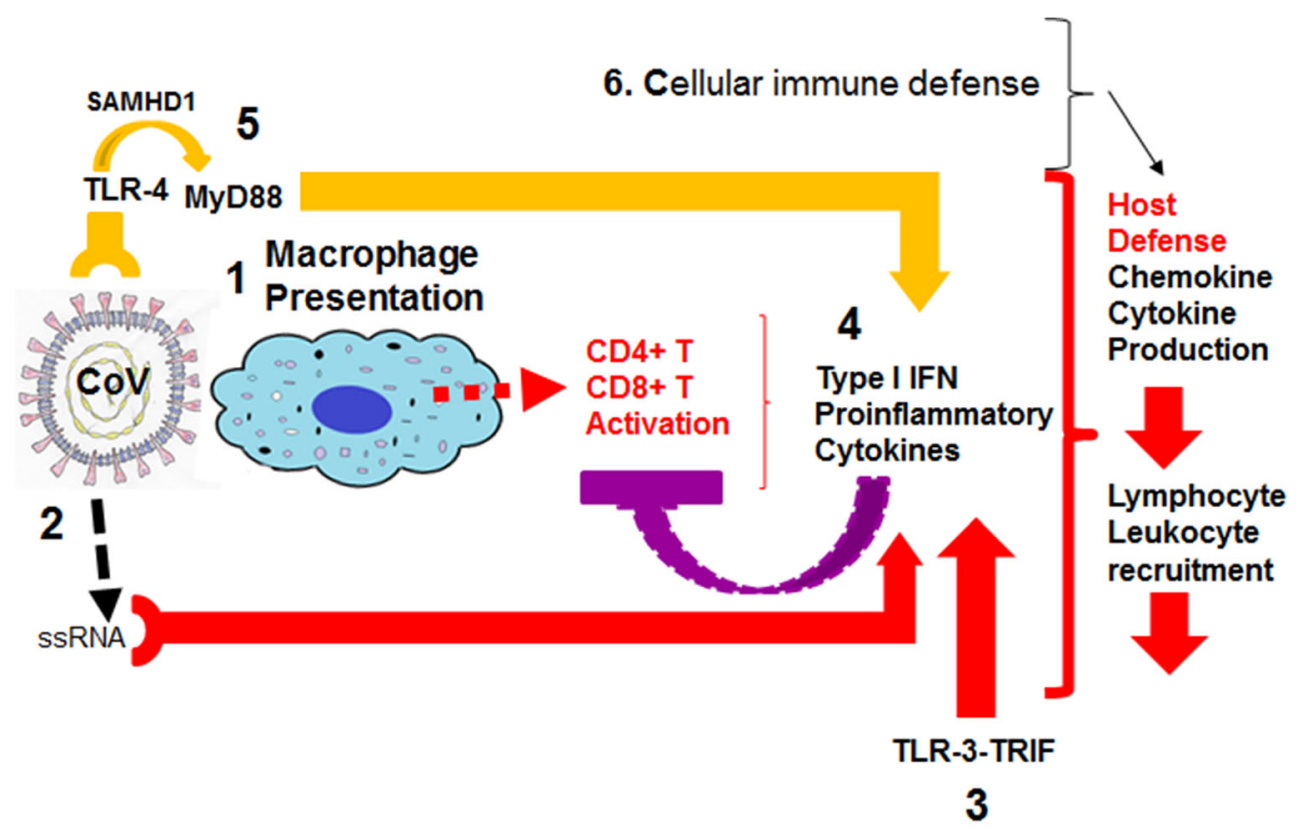

Fig. 1 Host immune defense towards coronavirus infections. The figure illustrates the major pathways host organism recognizes coronaviruses $(\mathrm{CoV})$ and responds. (1) Macrophage recognition and presentation to T cells, (3) activation of toll-like receptor 3 (TLR-3) signaling via TRIF, and (4) induction of type I interferon and downstream interferon response genes and cytokine secretion. Negative effect on CD4+ T and CD8+ T cells-purple line block. (5) Activation of SAMHD1 gene (upregulated

- Attachment of CoV to the host cell through their common spike (S) protein leads to the appearance of genomic RNA in the cytoplasm which induces an immune response to viral single-stranded RNA [6-8].

- TLR-3 activated by RNA further activates cascades of signaling pathways that induce type I IFNs and proinflammatory cytokine secretion $[9,10]$. However, in other coronavirus infections, it has been shown that accessory proteins may interfere with TLR-3 signaling and prevent TLR-3 activation and evade the immune response. It has been previously suggested that TLR-3 activation is protective against MERS-CoV infection [6].

- Another hypothetical viral response suggested is via TLR-4 recognizing S protein leading to activation of pro-inflammatory cytokines through the MyD88dependent signaling pathway [11-13]. Thus, virus-cell interactions lead to the strong production of immune mediators. Additionally, infected cells in response to $\mathrm{CoV}$ infection secrete large quantities of chemokines and cytokines (IL-1, IL-6, IL-8, IL-21, TNF- $\beta$, and MCP-1). These chemokines and cytokines, in turn, recruit lymphocytes and leukocytes to the site of infection and contribute to cytokine storm.

SARS-CoV-2 is also observed to cause viral sepsis, and the subsequent initial immune response is an elevation of pro-inflammatory cytokines and a severe immune during viral infections) triggering TLR-4 and MyD88-independent signaling activation leading to type I interferon and cytokine release. (6) Additionally, infected cells respond with the secretion of cytokines and chemokines for lymphocyte and leukocyte recruitment. SAMHD1; SAM and HD domain containing deoxynucleoside triphosphate triphosphohydrolase 1

dysregulation phase which follows an immune suppression phase. In the latter, almost all cells that play important roles in viral response seem to be substantially reduced in peripheral blood and become dysfunctional. These are mainly CD4+, CD8+ T cells, natural killer (NK) cells [14].

Plenty of Publications Have Been Suggesting that During SARS-CoV-2 Infection Host Defense Seems to be Impaired and It Could Be at Different Phases of Immune Defense Which Are Reflected in the Clinical Phases of the Infection. Some Speculations Are as Follows:

1. SARS-CoV-2 infection escapes the activation of interferon signaling and results in disseminated infection. Clinically, patients experience mild flu-like symptoms within approximately 1 week, which decline by the end of that week.

2. Activation and expansion of CD8+T cells and CD4+T cells are missing. Patients develop severe lymphopenia in the second week of illness. T-Cells, T helper 17, natural killer (NK), and B-cells are also diminished from peripheral blood. In this second phase of the infection, viral titers are reported lower in peripheral blood, while tissue inflammation in the lungs (pneumonia) continues. In this 
phase, depletion of CD8+T cell counts was suggested to

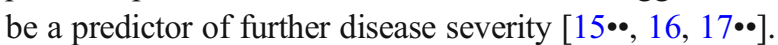
The accelerated immune response leads to adult respiratory distress syndrome (ARDS), with additional endorgan damage and shock. There is severe cytokine production (cytokine storm), lymphocyte depletion, and dysfunction.

3. Recovery phase (4-6 weeks): Patients clinically feel better, but some still require pulmonary and cardiac rehabilitation.

In contrast to adults, pediatric COVID-19 infection is asymptomatic $90 \%$ of the time. The most common clinical symptoms are cough (48\%), fever (41\%), diarrhea $(8.8 \%)$, and vomiting (6.7\%) (https://www.cdc.gov/coronavirus/ 2019-ncov/daily-life-coping/children/symptoms.html). In infants under 12 months of age, there is also poor appetite and feeding problems. Nasal congestion, loss of taste and smell, sore throat, headache, stomachache, fatigue, and muscle pain incidence seems to be similar to adult COVID19 infection. Laboratory findings also mirror adult infection with low CD4+ and CD8+ T-cells but high neutrophils, elevation in hepatic enzymes, hyperglycemia, elevated procalcitonin, but low c3 and c4 levels. There is still impaired activation of interferon-alpha (IFN- $\alpha)$ and interferon regulator 3 (IFNR3). While chest X-rays are mostly normal, chest CTs were more sensitive in detecting the lung pathology. Risk factors behind the severe disease in children were suggested to correlate with younger age, the higher percentage of neutrophils, higher LDH, decreased CD4+ and CD8+ T cells, and progressive pulmonary images. Nevertheless, most investigators report mild flu-like illness in children with COVID-19, and all recover in 1-2 weeks $[18,19]$. The mortality rate of all hospitalized children so far has been $0.18 \%$.

Theories behind why children are affected less by COVID-19 have been reviewed elsewhere [20]. There is still no scientific explanation so far why children have a less serious disease.

While effective anti-viral therapy is needed, effective modulation of innate immune response and restoring the adaptive immune system is suggested to be the essential actions in preventing mortality $[21 \bullet \bullet]$.

\section{COVID-19/MIS-C Pandemic Timeline}

SARS-CoV-2 was identified in Wuhan, China, in December 2019 [22••]. Initial reports of severe hyperinflammatory syndrome started to be reported in children first in the UK [23] and Spain [24] by April 2020. The first reports from the USA came from New York on April 27 $7^{\text {th }}, 2020$ [25]. During the following weeks, reports of increased incidence of Kawasaki disease were published [26]. On May $14^{\text {th }}$ CDC (https:// emergency.cdc.gov/han/2020/han00432.asp) and on May $15^{\text {th }}$ WHO published MIS-C definition (https://www. who.int/publications/i/item/multisystem-inflammatorysyndrome-in-children-and-adolescents-with-covid-19). Finally, the American College of Rheumatology (ACR) published consensus and treatment guidelines followed by publications from the pediatric rheumatology ACR COVID-19 task force $[27 \bullet \bullet$. The guidelines are online and are subject to change adjusting to current scientific information.

Multiple reports from around the world about the natural course of MIS-C and its epidemiology have been published following initial reports from Europe regarding MIS-C [25, 28, 29•, 30-53]. Most studies compared MIS-C with severe COVID-19 shock and Kawasaki disease [26, 35, 39, 41, 44, 54-87].

\section{Role of Pediatric Rheumatologist in COVID-19 Pandemic}

Pediatric rheumatologists have been obligated to get involved in post-COVID-19 illness definitions since post-COVID-19 syndromes in both adults and pediatrics resembled severe macrophage activation syndrome (MAS), systemic vasculitis with cardio myocardiopathy, and Kawasaki like a disease with coronary artery aneurysms. Variety of other known autoimmune disease onset resembled the features of COVID-19. Thus rheumatologic diseases became the top differential diagnosis such as hemolytic uremic syndrome [88], macrophage activation syndrome [71], inflammatory bowel disease [89], but mostly with Kawasaki disease [55, 56].

\section{Resemblance to MAS}

Rheumatologists were consulted frequently as to whether patients' post-COVID-19 syndrome had MAS since it showed similarities and responded to MAS treatment protocols. While ESR is classically low in MAS, in MIS-C, it is remarkably high. While splenomegaly is a hallmark of MAS, it is not seen in MIS-C. Associated cytokine storm in MAS is not identical to what is seen in post-COVID-19 illnesses [71].

\section{Resemblance to Immune Complex Vasculitis}

In MIS-C, there is a significant amount of acro-ischemia reported which was hypothetically explained with occlusion of blood vessels with immune complexes including spike proteins and anti-spike immunoglobulins. This resembles hepatitis B-related polyarteritis nodosa (PAN) with immune complexes containing HBsAg. Similar vasculitis is also seen in deficiency of adenosine deaminase 2 (ADA2). 


\section{Skin Lesions Resemble Pediatric Rheumatological Disease Manifestations}

Particularly with the pediatric age group, a variety of cases with skin rash associated with COVID-19 infection have been reported. These rashes were described as violaceous macules, livedoid rash, and palpable purpura (necrotic and nonnecrotic) that resembled Henoch-Schönlein Purpura [90].

\section{Resemblance to Kawasaki Disease}

Early studies (case reports) listed their findings (symptoms) of severe hyperinflammatory syndrome COVID-19, which resembled Kawasaki disease [64] from the UK [23, 91], Italy [26], Spain [24], and New York City [92].

In general, MIS-C diagnosis criteria are distinct with the involvement of myocardium and significant lymphopenia, neutrophilia, but an elevation of thrombocytopenia and ferritin levels in peripheral blood. Most MIS-C definitions agree with each other's criteria published by different organizations [25] (https://www.cdc.gov/mis-c/, https://health.ny.gov/press/ releases/2020/docs/2020-05-13_health_advisory.pdf, https:// www.who.int/news-room/commentaries/detail/multisysteminflammatory-syndrome-in-children-and-adolescents-withcovid-19). Initial striking difference in Kawasaki disease criteria is the significant thrombocytosis observed after the initial febrile stage and the involvement of coronary arteries as compared to predominant myocardial involvement seen in MIS-C.

When the symptoms and findings are categorized and lined up in different MIS-C definitions, it is noticeable that the CDC definition specifically does not include skin rash in MIS-C criteria. World Health Organization definition somewhat limits the case definition to those who experience fever continuously for more than 3 days, while others accept 1 day of fever as a major criterion. Another debated criterion is the presence of RT-PCR for SARS-CoV-2, which is not always present in MIS-C patients, versus evidence for IgG or IgM suggesting active or previous infection with SARS-CoV-2. Almost all suggested diagnostic criteria for MIS-C published by ACR task force, NY State case definition, WHO, and CDC criteria accept an epidemiologic link (contact exposure history) to SARS-CoV-2 infection, such as close contact with someone who had SARS-CoV-2. The presence of an epidemiologic link in MIS-C diagnostic criteria is particularly important since at the time those recommendations were made, in some centers, tests for SARS-CoV-2 infection with PCR or serology were either not available, or reliable, or processed promptly.

Worldwide pediatric healthcare communities and healthcare providers quickly became familiar with this lateonset multisystem involving inflammatory syndrome as a post-viral COVID-19 pediatric disease. Multiple case series and collaborative work collecting systematic data continued to unravel the diseases' clinical presentation patterns [27••, 84, 93-105]. The distinction from Kawasaki disease and macrophage activation syndrome from MIS-C became clearer with state-of-the-art molecular technological approaches [39, 92-94].

According to the US Health Department (December 9, 2020), the majority of the MIS-C population described is from Hispanic or Latino and black ethnicity $(75 \%), 99 \%$ of them are tested positive 2-4 weeks after a known infection or exposure to someone with the documented infection. Race and ethnicity seem to vary based on the region of the reports. While the State of Texas had more AfricanAmerican/Afro-Caribbean than others, California State showed more incidence for the Hispanic population.

Unlike in adults, the only significantly associated comorbidity with mortality due to MIS-C was obesity across all epidemiologic studies $(25-50 \%)$ [15••, 18, 36].

Recently, there have been multiple subsequent publications that described the clinical and laboratory features, the natural progress of MIS-C, and its epidemiology in various regions of the world. In this review, we will focus the discussion on those publications that provided some evidence for the distinction of the MIS-C from other overlapping or resembling pediatric syndromes.

\section{Is MIS-C Different from Kawasaki? If Yes, What Is Different and How Do We Differentiate the Two from Each Other?}

The initial reports about a multisystem inflammatory syndrome affecting children came from the UK [91], Spain [24], and then New York City in April 2020 [25]. In the following weeks, Italian pediatric rheumatologists reported a significant increase in Kawasaki syndrome in Italy [23, 26]. When those reports were assessed, it was a Kawasaki lie disease but in an older pediatric population. There were clear similarities to Kawasaki in these MIS-C cases. Some patients who immediately developed hemodynamic shock even further resembled the Kawasaki shock syndrome. More obvious differences were present between these two extreme presentations of Kawasaki disease shock and MISC shock.

MIS-C shock cases showed laboratory abnormalities that were more significantly abnormal compared to Kawasaki shock. Both patient populations that developed shock showed elevation of CRP and ferritin levels but lower in shock related with Kawasaki disease. In MIS-C again, the ethnicity of the patient population was predominantly African-American/ Hispanic, while Kawasaki patients that developed shock were more of Asian descent. Other distinct differences are as follows: while COVID-19 patients developed lymphopenia, low 
platelet counts, and low albumin levels, Kawasaki patients in shock developed no lymphopenia, less significant thrombocytopenia which reversed within the following 10-14 days and become thrombocytosis which persisted for many weeks. In those patients that develop shock after COVID-19, platelet counts normalize after the acute phase is over. The most distinct clinical feature of the MIS-C from Kawasaki is its myocardial involvement causing significant myocardial dysfunction with laboratory markers of troponin and BNP elevation. In Kawasaki, the most severely diseased patient's coronary artery involvement and secondary cardiac dysfunction are predominant. The levels of BNP and troponin were mildly elevated [106-109].

With the goal of identifying MIS-C immune activation difference from Kawasaki disease. Consiglio et al. [110••] performed a system analysis of immune cells, cytokines, and antibodies of patients with Kawasaki disease $(n=28)$, MIS-C patients $(n=13)$, children infected with SARS-CoV2 , and healthy children $(n=19)$.

Results of the principal analysis showed that MIS-C overlaps to an extent to both Kawasaki and adult hyperimmune syndrome following COVID-19, but most cytokine profiles were distinct in each of these subgroups. Principal component 2 showed more similarities in the cytokine profiles of MIS-C and SARS-CoV-2 infected children but differed in Kawasaki disease patients. The remarkable differences were for IL-6, IL17, CXCL10, ADA, and stem cell factor (SCF). In Kawasaki, IL-6, IL-17, and CXCL10 were homogeneously expressed at higher levels as compared to the MIS-C and SARS-CoV-2positive patients. However, between the MIS-C and SARS$\mathrm{CoV}-2$ positive patients, the levels showed more heterogeneous levels but with less significant differences between the groups suggesting a spectrum rather than two different diseases.

More importantly, this study using the proteome array profiling method showed that in healthy children, SARS-CoV-2infected patients, and in Kawasaki patients, there is immunity towards previously known other coronavirus antibodies (human coronavirus 1 and cattle beta coronavirus) that were present but surprisingly negative in all MIS-C patients cohorts. Before the importance of this finding and relevant immune activation pathways related to coronavirus infections should be discussed, it may be safer if this data is replicated in larger series.

Authors found Endoglin antibody presence in both MIS-C and Kawasaki patients. Marker for endothelial damage is found in the vascular endothelium and the heart muscle. But in MIS-C MAP2K2 and casein kinase, family members (CSNK1A1, CSNK2A1, CSNK1E1) were found to be exclusive. A potent anti-viral Silmitasertib (CX-4945), known to inhibit the activity of these kinases, was suggested to be used in COVID-19 patients as an adjunct therapy. Silmitasertib is currently in a clinical trial for age 18 and above patients with
COVID-19 infection (NCT04668209). On the other hand, Kawasaki patients in this study showed more plasma markers of arterial damage as compared to MIS-C. Autoantibodies towards epidermal growth factor-like repeats and discoidin I-like domains 3 (EDIL3) are known to play important role in vessel wall regeneration, remodeling, and angiogenesis expressed only in Kawasaki disease but not in MIS-C.

Proteome analysis indicates that although there is a variety of overlap, MIS-C and Kawasaki disease have different pathway activation, different targeted structure abnormalities, and abnormal markers of damage such as vascular endothelium vs myocardium.

The data from the largest international series of children with MIS-C ( $n=183$ ) (33 European, Asian and American hospitals) showed a more severe presentation of MIS-C. More than $40 \%$ of patients with MIS-C presented to the pediatric urgent care with shock. In summary, the international data of MIS-C patients had higher levels of BNP, D-dimer, CRP, and ferritin and developed more cardiac complications than Kawasaki patients, especially pericardial effusion, valvulitis, and left ventricular dysfunction requiring inotropic support, mechanical ventilation, and a longer duration of hospitalization. Only $15 \%$ of these MIS-C patients also fulfilled the criteria for KD. Kawasaki disease patients had a remarkably better clinical presentation, stability, and very few cardiac abnormalities other than coronary artery dilatations [36]. Efforts to identify the genes that are activated or downregulated during Kawasaki and MIS-C disease showed overlapping pathways but also distinct transcriptional signatures of MIS-C and pediatric COVID-19 transcriptional signatures [111].

\section{How Different Are COVID-19 Infection and MIS-C from Each Other?}

Ahmed et al. [29] tried to identify the differences between COVID-19 infection and MIS-C. The study showed that MIS-C cases epidemiologically followed the COVID-19 infection by 5.3 weeks after the pandemic started. Thus MIS-C did not start at the beginning of the pandemic with the acutely infected patients. When the overlapping symptoms such as fever are seen in both groups, in COVID-19 patients, predominant symptoms are cough and rhinorrhea, while in MIS-C patients, it is more diarrhea, vomiting, and skin rash. The differences between the predominant clinical presentation of COVID-19 and MIS-C were confirmed by many other investigators in different series around the world [33].

Further attempts to clarify the differences between the acute COVID-19 infection and MIS-C were performed by Diorio et al. [112••]. They prospectively enrolled and followed three groups of patients with mild COVID-19 infections, 
severe COVID-19 infections, and those that developed MIS-C between April $3^{\text {rd }}$ and May $15^{\text {th }}, 2020$. Results showed that in all three groups of patients, there was significant innate immunity dysfunction evident from elevated cytokines (IL-6, IL-8, and TNF-alpha), lymphopenia, presence of co-infection, and elevated markers of endothelial dysfunction such as C5b-9. Abnormal erythrocyte phenotype (schistocytes, burr cells, toxic granulation) was seen in all but showing significantly increased percentage with severe COVID-19 infection and maximum abnormality in MIS-C patients. However, there were significant differences between the COVID-19 and MIS-C cases. In severe COVID-19 infection, patients showed abnormalities that we see in MAS such as ferritin, transaminase, lactate, and prothrombin elevation with significant thrombocytopenia. Serum interferon-gamma levels were significantly elevated during active infection, and RT-PCR performed to detect SARS-CoV-2 had low cycle threshold $(\mathrm{Ct})$ counts representing high viral load (Ct counts are inversely proportional to the amount of target nucleic acid in the sample). Patients were mostly between 13 and 16 years old. In the MIS-C cohort, the laboratory findings suggested more vascular injury and cardiac involvement with high levels of troponin, D-dimer, and B type natriuretic peptide (BNP). IL-10 and TNF- $\alpha$, when analyzed together, were more significantly elevated but not the interferon-gamma with very high levels of Ct counts in SARS-CoV-2 PCRs tests. High Ct counts in RT-PCR representing low viral load or perhaps only residual RNA belonging to viral particles left from the already recovered viral infection. The patient group in MIS$\mathrm{C}$ was much younger (6-8 years old). These results suggested that MIS-C is an immune activation syndrome but not an acute infectious process, and patients do not currently have active SARS-CoV-2 infection, but lingering viral RNA determined by RT-PCR.

Later, Vella et al. [113] in a similar study also compared the adult and pediatric COVID-9 infections which differed from pediatric MIS-C. In the MIS-C cohort, it is observed that there is continued activation of adaptive immune response driven by persistent antigen presence. It is possible that in younger children, the host response to SARS-CoV-2 is not necessarily robust; they experience a very mild underdiagnosed acute infection period in which host immune activation is not able to clear the system from the virus completely; thus a persistent antigen stimulation exists. In MIS-C patients, peripheral blood CD8+T cells, particularly vascular patrolling CX3CR1+ $\mathrm{CD} 8+\mathrm{T}$ cells, are significantly elevated as compared to acutely COVID-19-infected patients. The same group found a correlation between decreasing levels of HLA-DR+ CD38+T cell population and clinical improvement in MIS-C. However, there is also evidence that cytotoxic $\mathrm{CD} 8+\mathrm{T}$ cells are dysregulated, and there is CD8+T cell exhaustion in MIS-C, which can also be seen in Kawasaki disease to some degree [111]
Carter et al. [114*•] from the UK used another approach and analyzed the MIS-C patients at different time points: acute $(\mathrm{T} 1, \mathrm{n}=23)$, resolution $(\mathrm{T} 2, \mathrm{n}=14)$, and during convalescent phase $(\mathrm{T} 3, \mathrm{n}=10)$. They found high HLA-DR expression on $\gamma \delta$ and CD4+ CCR7+ T cells in the acute phase, which suggested that these immune cell populations were activated and stayed activated through T3. They showed that in peripheral blood, the antigen-presenting cells had low HLA-DR and CD86 expression, potentially indicative of impaired antigen presentation. Surprisingly, both in the reports of Vella et al. and Carter et al., data suggests evidence that both antigen and host response are impaired in MIS-C which may lead continuous antigenic simulation and chronic adaptive immune response. Carter et al. suggested that there are two immune pathogenic drivers of MIS-C, one is the altered interferongamma response, and the other one is antibody-dependent enhancement of the disease and adaptive immune reaction. Another study by Anderson et al. showed that children with MIS-C have higher levels of IgG antibodies that neutralize SARS-CoV-2 more effectively compared to children with severe COVID-19, suggesting the presence of a stronger adaptive immune system response in MIS-C [115]. Unfortunately, there are still wide presentation differences of SARS-CoV-2 infections and MIS-C between patients which could be due to their genetic background, such as HLA alleles. Patients show up in the clinics with huge variability in their clinical presentations and laboratory markers.

In summary, it appears clear that MIS-C and COVID-19 are distinct presentations of SARS-CoV-2 infection, dependent on the initial antigenic clearance. Children at a younger age may not have the fully developed immune system to clear the antigen completely. Therefore, they may develop MIS-C after mostly an asymptomatic COVID-19 infection.

Furthermore, previous similar coronavirus infection other than SAR-CoV2 seems to be protective against MIS-C, while patients still develop Kawasaki disease and COVID19 infection (Fig. 2). While the COVID-19 pandemic is more controlled, the incidence of infected patients decreased, and the incidence of MIS-C cases is decreasing in Europe [32]. Once a vaccine for SARS-CoV-2 becomes available for children, MIS-C may not be as common and perhaps disappear.

\section{Conclusions}

We are still learning from worldwide collaborative studies about pediatric COVID-19 infection and MIS-C. Most of our efforts are spent trying to successfully differentiate between Kawasaki and MIS-C. There are plenty of clinical and laboratory findings, cellular phenotype data, and antibody data showing somewhat similar but mostly distinct markers at least between Kawasaki and MIS-C. However, pediatric mild 
Fig. 2 Distinct and overlapping features of MIS-C, Kawasaki disease, and severe COVID-19 disease in children listed in a Venn diagram. EDIL3, endothelial growth factor-like repeats; MAP2K2, map kinase; BNP, B-type natriuretic peptide; SCF, stem cell factor; TWEAK, TNF-related weak inducer of apoptosis; ADA, adenosine deaminase; HKU1, human coronavirus 1 (alpha); B CoV 1, betacoronavirus 1 (human and cattle); ESR, erythrocyte sedimentation rate; $\mathrm{CRO}, \mathrm{C}$ reactive protein

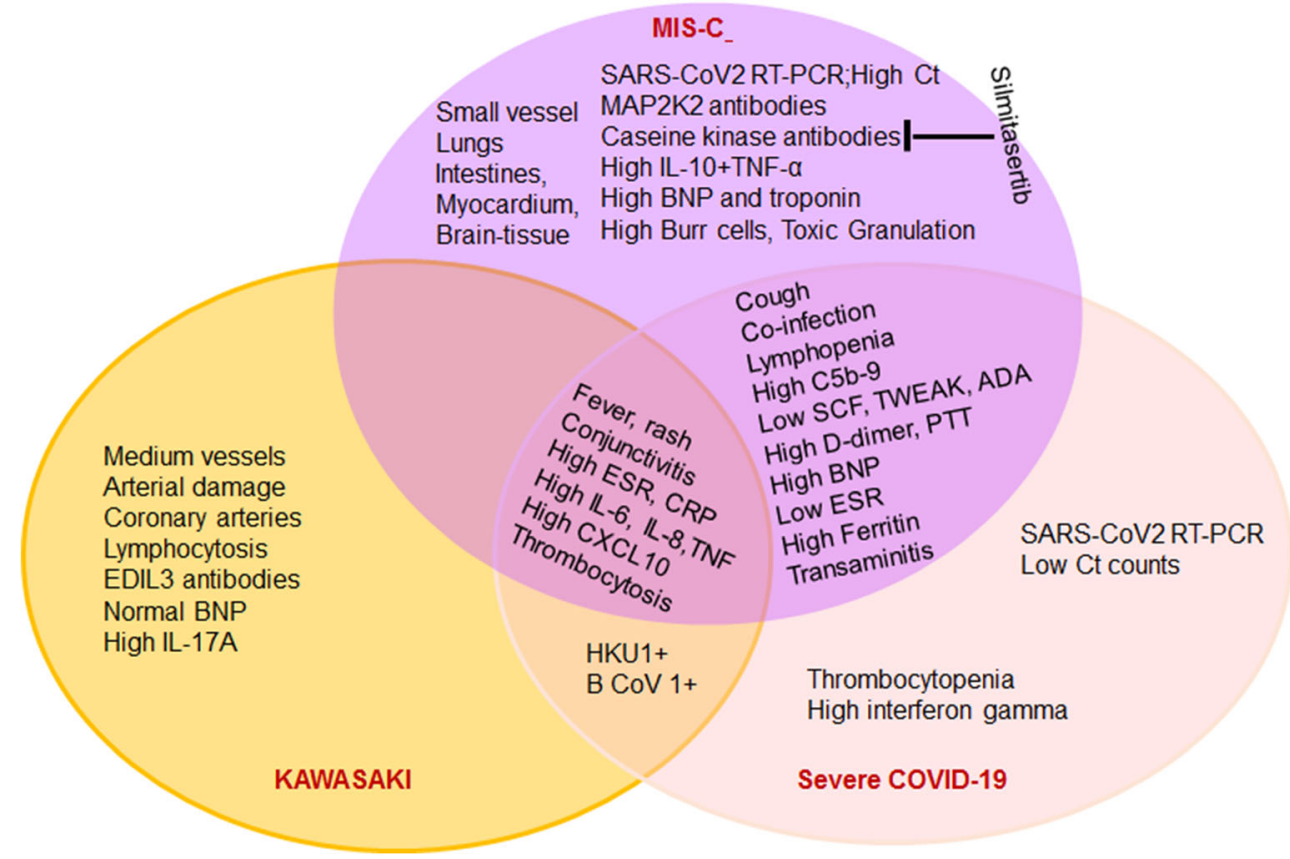

COVID-19 disease and MIS-C seem to be presentations of a spectrum of the host response to SARS-CoV-2 infection. The host response could be anything from an acute innate response to late adaptive response. Certainly, there is a lot to learn about the heterogeneous host response to SARS-CoV-2 infection in both adults and children.

Suggestions of a continuous antigenic stimulus, inability to clear the viral infection, in younger pediatric patients developing MIS-C may raise the question of whether children are truly the silent spreaders of SARS-CoV2. They may develop severe MIS-C. Since most MIS-C patients are 6-7 year old children, should we reconsider primary school students' continue in remote learning?

Fortunately, MIS-C responds well to aggressive therapy protocols implemented from Kawasaki disease with high dose IVIG, high dose corticosteroid, interleukin 1 (IL-1) inhibition, and anti-coagulation with aspirin. Multiple algorithms of treatment approaches have been published, and recommendations from the ACR rheumatology task force are a live document that changes when there is newer information providing the most accurate support in decision-making for diagnosis and treatment. So far most patients are discharged home with no major complication on maintenance treatment with oral steroids, aspirin, and quickly weaned off these medications in a few weeks, once cardiology clears the patients from a cardiac function to stand point.

In the current pandemic era, MIS-C claimed the title of "most common acquired pediatric cardiac disease" from Kawasaki disease, subject to change when the vaccinations are available for the pediatric patient population.

\section{References}

Papers of particular interest, published recently, have been highlighted as:

- Of importance

•. Of major importance

1. Chu H, Chan JF, Wang Y, Yuen TT, Chai Y, Hou Y, et al. Comparative replication and immune activation profiles of SARS-CoV-2 and SARS-CoV in human lungs: an ex vivo study with implications for the pathogenesis of COVID-19. Clin Infect Dis. 2020;71(6):1400-9. https://doi.org/10.1093/cid/ciaa410.

2. Chu H, Zhou J, Wong BH, Li C, Chan JF, Cheng ZS, et al. Middle East respiratory syndrome coronavirus efficiently infects human primary $\mathrm{T}$ lymphocytes and activates the extrinsic and intrinsic apoptosis pathways. J Infect Dis. 2016;213(6):904-14. https:// doi.org/10.1093/infdis/jiv380.

3. Chen J, Subbarao K. The immunobiology of SARS*. Annu Rev Immunol. 2007;25:443-72. https://doi.org/10.1146/annurev. immunol.25.022106.141706.

4. Libraty DH, O'Neil KM, Baker LM, Acosta LP, Olveda RM. Human CD4(+) memory T-lymphocyte responses to SARS coronavirus infection. Virology. 2007;368(2):317-21. https://doi.org/ 10.1016/j.virol.2007.07.015.

5. Li CK, Wu H, Yan H, Ma S, Wang L, Zhang M, et al. T cell responses to whole SARS coronavirus in humans. J Immunol. 2008;181(8):5490-500. https://doi.org/10.4049/jimmunol.181.8. 5490.

6. Totura AL, Baric RS. SARS coronavirus pathogenesis: host innate immune responses and viral antagonism of interferon. Curr Opin Virol. 2012;2(3):264-75. https://doi.org/10.1016/j.coviro.2012. 04.004.

7. Totura AL, Whitmore A, Agnihothram S, Schafer A, Katze MG, Heise MT, et al. Toll-like receptor 3 signaling via TRIF contributes to a protective innate immune response to severe acute 
respiratory syndrome coronavirus infection. mBio. 2015;6(3): e00638-15. https://doi.org/10.1128/mBio.00638-15.

8. Liu S, Xiao G, Chen Y, He Y, Niu J, Escalante CR, et al. Interaction between heptad repeat 1 and 2 regions in spike protein of SARS-associated coronavirus: implications for virus fusogenic mechanism and identification of fusion inhibitors. Lancet. 2004;363(9413):938-47. https://doi.org/10.1016/S01406736(04)15788-7.

9. Cameron MJ, Ran L, Xu L, Danesh A, Bermejo-Martin JF, Cameron CM, et al. Interferon-mediated immunopathological events are associated with atypical innate and adaptive immune responses in patients with severe acute respiratory syndrome. $\mathrm{J}$ Virol. 2007;81(16):8692-706. https://doi.org/10.1128/JVI. 00527-07.

10. Cameron MJ, Bermejo-Martin JF, Danesh A, Muller MP, Kelvin DJ. Human immunopathogenesis of severe acute respiratory syndrome (SARS). Virus Res. 2008;133(1):13-9. https://doi.org/10. 1016/j.virusres.2007.02.014.

11. Khanmohammadi S, Rezaei N. Role of Toll-like receptors in the pathogenesis of COVID-19. J Med Virol. 2021;93(5):2735-9. https://doi.org/10.1002/jmv.26826.

12. Gadanec LK, McSweeney KR, Qaradakhi T, Ali B, Zulli A, Apostolopoulos V. Can SARS-CoV-2 virus use multiple receptors to enter host cells? Int J Mol Sci. 2021;22(3). https://doi.org/10. 3390/ijms22030992.

13. Aboudounya MM, Heads RJ. COVID-19 and Toll-Like Receptor 4 (TLR4): SARS-CoV-2 may bind and activate TLR4 to increase ACE2 expression, facilitating entry and causing hyperinflammation. Mediators Inflamm. 2021;2021:887433918. https://doi.org/10.1155/2021/8874339.

14. Chen G, Wu D, Guo W, Cao Y, Huang D, Wang H, et al. Clinical and immunological features of severe and moderate coronavirus disease 2019. J Clin Invest. 2020;130(5):2620-9. https://doi.org/ 10.1172/JCI137244.

15.• Wang Y, Zhu F, Wang C, Wu J, Liu J, Chen X, et al. Children hospitalized with severe COVID-19 in Wuhan. Pediatr Infect Dis J. 2020;39(7):e91-e4. https://doi.org/10.1097/INF. 0000000000002739 This article reports the initial pediatric cases affected from COVID-19 infection in it epicenter.

16. Wang Z, Ye D, Wang M, Zhao M, Li D, Ye J, et al. Clinical features of COVID-19 patients with different outcomes in wuhan: a retrospective observational study. Biomed Res Int. 2020;2020: 2138387-10. https://doi.org/10.1155/2020/2138387.

17.• Wang Z, Zhou Q, Wang C, Shi Q, Lu S, Ma Y, et al. Clinical characteristics of children with COVID-19: a rapid review and meta-analysis. Ann Transl Med. 2020;8(10):620. https://doi.org/ 10.21037/atm-20-3302 This article review pediatric cases retrospectively to assess co morbidities.

18. Lu X, Zhang L, Du H, Zhang J, Li YY, Qu J, et al. SARS-CoV-2 infection in children. N Engl J Med. 2020;382(17):1663-5. https:// doi.org/10.1056/NEJMc2005073.

19. Cui X, Zhao Z, Zhang T, Guo W, Guo W, Zheng J, et al. A systematic review and meta-analysis of children with coronavirus disease 2019 (COVID-19). J Med Virol. 2021;93(2):1057-69. https://doi.org/10.1002/jmv.26398.

20. Batu ED, Ozen S. Implications of COVID-19 in pediatric rheumatology. Rheumatol Int. 2020;40(8):1193-213. https://doi.org/ $10.1007 / \mathrm{s} 00296-020-04612-6$.

21.• Li H, Liu L, Zhang D, Xu J, Dai H, Tang N, et al. SARS-CoV-2 and viral sepsis: observations and hypotheses. Lancet. 2020;395(10235):1517-20. https://doi.org/10.1016/S01406736(20)30920-X Article explains the viral infection by COVID-19 and hypothetical mechanisms of infection.
22.• Huang C, Wang Y, Li X, Ren L, Zhao J, Hu Y, et al. Clinical features of patients infected with 2019 novel coronavirus in Wuhan, China. Lancet. 2020;395(10223):497-506. https://doi. org/10.1016/S0140-6736(20)30183-5 Original paper that reported the COVID-19 infection in Wuhan China.

23. Riphagen S, Gomez X, Gonzalez-Martinez C, Wilkinson N, Theocharis P. Hyperinflammatory shock in children during COVID-19 pandemic. Lancet. 2020;395(10237):1607-8. https:// doi.org/10.1016/S0140-6736(20)31094-1.

24. Moraleda C, Serna-Pascual M, Soriano-Arandes A, Simo S, Epalza C, Santos M, et al. Multi-inflammatory syndrome in children related to SARS-CoV-2 in Spain. Clin Infect Dis. 2020;72: e397-401. https://doi.org/10.1093/cid/ciaa1042.

25. Dufort EM, Koumans EH, Chow EJ, Rosenthal EM, Muse A, Rowlands $\mathrm{J}$, et al. Multisystem inflammatory syndrome in Children in New York State. N Engl J Med. 2020;383(4):34758. https://doi.org/10.1056/NEJMoa2021756.

26. Verdoni L, Mazza A, Gervasoni A, Martelli L, Ruggeri M, Ciuffreda M, et al. An outbreak of severe Kawasaki-like disease at the Italian epicentre of the SARS-CoV-2 epidemic: an observational cohort study. Lancet. 2020;395(10239):1771-8. https://doi. org/10.1016/S0140-6736(20)31103-X.

27.• Henderson LA, Canna SW, Friedman KG, Gorelik M, Lapidus SK, Bassiri H, et al. American College of Rheumatology Clinical Guidance for Multisystem Inflammatory Syndrome in Children Associated With SARS-CoV-2 and Hyperinflammation in Pediatric COVID-19: Version 1. Arthritis Rheumatol. 2020;72(11):1791-805. https://doi.org/10.1002/art.41454 This is the first publication that described the efforts of American Caollege of Rheumatology designing the definition criteria and treatment recommendations for MIS-C. Currently all pediatric rheumatologists are following these original guidelines.

28. Abrams JY, Godfred-Cato SE, Oster ME, Chow EJ, Koumans $\mathrm{EH}$, Bryant B, et al. Multisystem inflammatory syndrome in children associated with severe acute respiratory syndrome coronavirus 2: a systematic review. J Pediatr. 2020;226:45-54.e1. https:// doi.org/10.1016/j.jpeds.2020.08.003.

29. Ahmed M, Advani S, Moreira A, Zoretic S, Martinez J, Chorath $\mathrm{K}$, et al. Multisystem inflammatory syndrome in children: A systematic review. EClinicalMedicine. 2020;26:100527. https://doi. org/10.1016/j.eclinm.2020.100527 Review article that showed one of the largest patient population affected from MIS-C and their demographic data.

30. Almoosa ZA, Al Ameer HH, AlKadhem SM, Busaleh F, AlMuhanna FA, Kattih O. Multisystem inflammatory syndrome in children, the real disease of COVID-19 in pediatrics - a multicenter case series from Al-Ahsa. Saudi Arabia Cureus. 2020;12(10):e11064. https://doi.org/10.7759/cureus.11064.

31. Alnashri H, Aljohani N, Tayeb S, Rabie N, AlBenayan E, Alharthi A, et al. A challenging case of multisystem inflammatory syndrome in children related to coronavirus Disease-19 hospitalized under adult medical service. IDCases. 2020;22:e00957. https:// doi.org/10.1016/j.idcr.2020.e00957.

32. Arditi M, Bahar I. Multisystem inflammatory syndrome in children in the United States. N Engl J Med. 2020;383(18):1794-6. https://doi.org/10.1056/NEJMc2026136.

33. Aronoff SC, Hall A, Del Vecchio MT. The natural history of SARS-Cov-2 related multisystem inflammatory syndrome in children (MIS-C): a systematic review. J Pediatric Infect Dis Soc. 2020;9:746-51. https://doi.org/10.1093/jpids/piaa112.

34. Bar-Or D, Rael LT, Brody EN. Insights into pediatric multisystem inflammatory syndrome and COVID-19. Clin Chim Acta. 2020;510:121-2. https://doi.org/10.1016/j.cca.2020.07.025. 
35. Bassareo PP, Calcaterra G, Fanos V. Coronavirus disease 2019, Kawasaki disease, and multisystem inflammatory syndrome in children. J Pediatr. 2020;224:184. https://doi.org/10.1016/j.jpeds. 2020.06.033.

36. Bautista-Rodriguez C, Sanchez-de-Toledo J, Clark BC, Herberg J, Bajolle F, Randanne PC, et al. Multisystem inflammatory syndrome in children: an international survey. Pediatrics. 2020;147: e2020024554. https://doi.org/10.1542/peds.2020-024554.

37. Belot A, Levy-Bruhl D. French Covid-19 Pediatric Inflammation C. Multisystem inflammatory syndrome in children in the United States. N Engl J Med. 2020;383(18):1793-4. https://doi.org/10. 1056/NEJMc2026136.

38. Bhat CS, Gupta L, Balasubramanian S, Singh S, Ramanan AV. Hyperinflammatory syndrome in children associated With COVID-19: need for awareness. Indian Pediatr. 2020;57(10): 929-35.

39. Bordet J, Perrier S, Olexa C, Gerout AC, Billaud P, Bonnemains L. Paediatric multisystem inflammatory syndrome associated with COVID-19: filling the gap between myocarditis and Kawasaki? Eur J Pediatr. 2020;180:877-84. https://doi.org/10.1007/s00431020-03807-0.

40. Buonsenso D, Riitano F, Valentini P. Pediatric inflammatory multisystem syndrome temporally related with SARS-CoV-2: immunological similarities with acute rheumatic fever and toxic shock syndrome. Front Pediatr. 2020;8:574. https://doi.org/10.3389/ fped.2020.00574.

41. Burgi Vieira C, Ferreira AT, Botelho Cardoso F, Pelicano Paulos J, Germano N. Kawasaki-like syndrome as an emerging complication of SARS-CoV-2 infection in young adults. Eur J Case Rep Intern Med. 2020;7(10):001886. https://doi.org/10.12890/2020 001886.

42. Carbajal R, Lorrot M, Levy Y, Grimprel E, Lecarpentier T, Heritier S, et al. Multisystem inflammatory syndrome in children rose and fell with the first wave of the COVID-19 pandemic in France. Acta Paediatr. 2020;110:922-32. https://doi.org/10.1111/ apa.15667.

43. Cavounidis A, Alderson J, Quastel M. Multisystem inflammatory syndrome in children: getting to the heart of the matter. Nat Rev Immunol. 2020;20(9):520. https://doi.org/10.1038/s41577-0200409-z.

44. Cogan E, Foulon P, Cappeliez O, Dolle N, Vanfraechem G, De Backer D. Multisystem inflammatory syndrome with complete Kawasaki disease features associated with SARS-CoV-2 infection in a young adult. A case report. Front Med (Lausanne). 2020;7: 428. https://doi.org/10.3389/fmed.2020.00428.

45. de Farias ECF, Pedro Piva J, de Mello M. do Nascimento L, Costa CC, Machado MMM, et al. Multisystem inflammatory syndrome associated with coronavirus disease in children: a multi-centered study in Belem, Para, Brazil. Pediatr Infect Dis J. 2020;39(11): e374-e6. https://doi.org/10.1097/INF.0000000000002865.

46. De Paulis M, Oliveira DBL, Vieira RP, Pinto IC, Machado RRG, Cavalcanti MP, et al. Multisystem inflammatory syndrome associated with COVID-19 with neurologic manifestations in a child: a brief report. Pediatr Infect Dis J. 2020;39(10):e321-e4. https://doi. org/10.1097/INF.0000000000002834.

47. Del Greco G, Brady K, Clark B, Park H. A novel pediatric multisystem inflammatory syndrome during the COVID-19 pandemic. Pediatr Emerg Care. 2020;36(10):500-4. https://doi.org/10. 1097/PEC.0000000000002229.

48. Dove ML, Jaggi P, Kelleman M, Abuali M, Ang JY, Ballan W, et al. Multisystem inflammatory syndrome in children: survey of protocols for early hospital evaluation and management. J Pediatr. 2020;229:33-40. https://doi.org/10.1016/j.jpeds.2020.10.026.

49. Farias ECF, Justino MCA, Mello M. Multisystem inflammatory syndrome in a child associated with coronavirus disease 19 in the Brazilian Amazon: fatal outcome in an infant. Rev Paul Pediatr. 2020;38:e2020165. https://doi.org/10.1590/1984-0462/2020/38/ 2020165.

50. Feldstein LR, Rose EB, Horwitz SM, Collins JP, Newhams MM, Son MBF, et al. Multisystem inflammatory syndrome in U.S. children and adolescents. N Engl J Med. 2020;383(4):334-46. https://doi.org/10.1056/NEJMoa2021680.

51. Felsenstein S, Willis E, Lythgoe H, McCann L, Cleary A, Mahmood K, et al. Presentation, Treatment response and shortterm outcomes in paediatric multisystem inflammatory syndrome temporally associated with SARS-CoV-2 (PIMS-TS). J Clin Med. 2020;9(10). https://doi.org/10.3390/jcm9103293.

52. Gerall CD, Duron VP, Griggs CL, Kabagambe SK, Maddocks AB, DeFazio JR. Multisystem inflammatory syndrome in children mimicking surgical pathologies: what surgeons need to know about MIS-C. Ann Surg. 2020;273:e146-8. https://doi.org/10. 1097/SLA.0000000000004368.

53. Gruber C, Patel R, Trachman R, Lepow L, Amanat F, Krammer F, et al. Mapping systemic inflammation and antibody responses in multisystem inflammatory syndrome in children (MIS-C). medRxiv. 2020. https://doi.org/10.1101/2020.07.04.20142752.

54. Berardicurti O, Conforti A, Ruscitti P, Cipriani P, Giacomelli R. The wide spectrum of Kawasaki-like disease associated with SARS-CoV-2 infection. Expert Rev Clin Immunol. 2020;16:111. https://doi.org/10.1080/1744666X.2021.1847643.

55. Butters C, Curtis N, Burgner DP. Kawasaki disease fact check: myths, misconceptions and mysteries. J Paediatr Child Health. 2020;56(9):1343-5. https://doi.org/10.1111/jpc.15101.

56. Calcaterra G, Mehta JL, Fanos V, Bassareo PP. Insights on Kawasaki disease and multisystem inflammatory syndrome; relationship with COVID-19 infection. Minerva Pediatr. 2020. https:// doi.org/10.23736/S0026-4946.20.06140-X.

57. Chang AJ, Croix M, Kenney P, Baron S, Hicar MD. Serum responses of children with Kawasaki disease against severe acute respiratory syndrome coronavirus 2 proteins. Pediatr Infect Dis J. 2020;39(11):e366-e7. https://doi.org/10.1097/INF. 0000000000002863.

58. Corwin DJ, Sartori LF, Chiotos K, Odom John AR, Cohn K, Bassiri $\mathrm{H}$, et al. Distinguishing multisystem inflammatory syndrome in children from Kawasaki disease and benign inflammatory illnesses in the SARS-CoV-2 pandemic. Pediatr Emerg Care. 2020;36(11):554-8. https://doi.org/10.1097/PEC. 0000000000002248 .

59. Ebina-Shibuya R, Namkoong H, Shibuya Y, Horita N. Multisystem inflammatory syndrome in children (MIS-C) with COVID-19: insights from simultaneous familial Kawasaki disease cases. Int J Infect Dis. 2020;97:371-3. https://doi.org/10. 1016/j.ijid.2020.06.014.

60. Elias MD, McCrindle BW, Larios G, Choueiter NF, Dahdah N, Harahsheh AS, et al. Management of multisystem inflammatory syndrome in children associated with COVID-19: a survey from the International Kawasaki Disease Registry. CJC Open. 2020;2(6):632-40. https://doi.org/10.1016/j.cjco.2020.09.004.

61. Falah NU, Hashmi S, Ahmed Z, Jaan A, Akhtar A, Khalid F, et al. Kawasaki disease-like features in 10 pediatric COVID-19 cases: a retrospective study. Cureus. 2020;12(10):e11035. https://doi.org/ 10.7759/cureus. 11035 .

62. Gaitonde M, Ziebell D, Kelleman MS, Cox DE, Lipinski J, Border WL, et al. COVID-19-Related multisystem inflammatory syndrome in children affects left ventricular function and global strain compared with Kawasaki disease. J Am Soc Echocardiogr. 2020;33(10):1285-7. https://doi.org/10.1016/j.echo.2020.07.019.

63. Garcia-Salido A, Cuenca-Carcelen S, Castillo-Robleda A. CD64, CD1 la and CD18 leukocytes expression in children with SARS$\mathrm{CoV}-2$ multisystem inflammatory syndrome versus children with Kawasaki disease: Similar but not the same. Med Clin (Barc). 2020;156:89-91. https://doi.org/10.1016/j.medcli.2020.09.002. 
64. Gkoutzourelas A, Bogdanos DP, Sakkas LI. Kawasaki Disease and COVID-19. Mediterr J Rheumatol. 2020;31(Suppl 2):26874. https://doi.org/10.31138/mjr.31.3.268.

65. Hosseini MS. Kawasaki or Kawasaki-like disease? A debate on COVID-19 infection in children. Clin Immunol. 2020;222: 108646. https://doi.org/10.1016/j.clim.2020.108646.

66. Iio K, Uda K, Hataya H, Yasui F, Honda T, Sanada T, et al. Kawasaki disease or Kawasaki-like disease: influence of SARSCoV-2 infections in Japan. Acta Paediatr. 2020;110:600-1. https://doi.org/10.1111/apa.15535.

67. Kabeerdoss J, Pilania RK, Karkhele R, Kumar TS, Danda D, Singh S. Severe COVID-19, multisystem inflammatory syndrome in children, and Kawasaki disease: immunological mechanisms, clinical manifestations and management. Rheumatol Int. 2020;41: 19-32. https://doi.org/10.1007/s00296-020-04749-4.

68. Kone-Paut I, Cimaz R. Is it Kawasaki shock syndrome, Kawasakilike disease or pediatric inflammatory multisystem disease? The importance of semantic in the era of COVID-19 pandemic. RMD Open. 2020;6(2). https://doi.org/10.1136/rmdopen-2020-001333.

69. Krasic S, Prijic S, Minic P, Petrovic G, Nesic D, Paripovic A, et al. Kawasaki-like disease and acute myocarditis in the SARS-CoV-2 pandemic - reports of three adolescents. Bosn J Basic Med Sci. 2020. https://doi.org/10.17305/bjbms.2020.5037.

70. Loke YH, Berul CI, Harahsheh AS. Multisystem inflammatory syndrome in children: is there a linkage to Kawasaki disease? Trends Cardiovasc Med. 2020;30(7):389-96. https://doi.org/10. 1016/j.tcm.2020.07.004.

71. Loomba RS, Villarreal EG, Flores S. COVID-19 and hyperinflammatory syndrome in children: Kawasaki disease with macrophage activation syndrome in disguise? Cureus. 2020;12(8):e9515. https://doi.org/10.7759/cureus.9515.

72. Masih M, Moll S, Raza N. Paediatric case of prolonged COVID19 manifesting as PMIS-TS and atypical Kawasaki. BMJ Case Rep. 2020;13(9). https://doi.org/10.1136/bcr-2020-237194.

73. Mazori DR, Derrick KM, Kapoor U, Haribhai M, Gist RE, Glick SA. Perineal desquamation: an early sign of the Kawasaki disease phenotype of MIS-C. Pediatr Dermatol. 2020;38:253-6. https:// doi.org/10.1111/pde.14462.

74. McCrindle BW, Manlhiot C. SARS-CoV-2-Related inflammatory multisystem syndrome in children: different or shared etiology and pathophysiology as kawasaki disease? JAMA. 2020;324(3): 246-8. https://doi.org/10.1001/jama.2020.10370.

75. Panupattanapong S, Brooks EB. New spectrum of COVID-19 manifestations in children: Kawasaki-like syndrome and hyperinflammatory response. Cleve Clin J Med. 2020. https:// doi.org/10.3949/ccjm.87a.ccc039.

76. Plebani A, Meini A, Cattalini M, Lougaris V, Bugatti A, Caccuri $\mathrm{F}$, et al. Mycoplasma infection may complicate the clinical course of SARS-Co-V-2 associated Kawasaki-like disease in children. Clin Immunol. 2020;221:108613. https://doi.org/10.1016/j.clim. 2020.108613

77. Pouletty M, Borocco C, Ouldali N, Caseris M, Basmaci R, Lachaume N, et al. Paediatric multisystem inflammatory syndrome temporally associated with SARS-CoV-2 mimicking Kawasaki disease (Kawa-COVID-19): a multicentre cohort. Ann Rheum Dis. 2020;79(8):999-1006. https://doi.org/10.1136/ annrheumdis-2020-217960.

78. Rauf A, Vijayan A, John ST, Krishnan R, Latheef A. Multisystem inflammatory syndrome with features of atypical Kawasaki disease during COVID-19 pandemic. Indian J Pediatr. 2020;87(9): 745-7. https://doi.org/10.1007/s12098-020-03357-1.

79. Rehman S, Majeed T, Ansari MA, Al-Suhaimi EA. Syndrome resembling Kawasaki disease in COVID-19 asymptomatic children. J Infect Public Health. 2020;13(12):1830-2. https://doi.org/ 10.1016/j.jiph.2020.08.003.
80. Rife E, Gedalia A. Kawasaki Disease: an Update. Curr Rheumatol Rep. 2020;22(10):75. https://doi.org/10.1007/s11926-020-009414.

81. Rowley AH. Multisystem inflammatory syndrome in children and Kawasaki disease: two different illnesses with overlapping clinical features. J Pediatr. 2020;224:129-32. https://doi.org/10.1016/j. jpeds.2020.06.057.

82. Sarzaeim M, Rezaei N. Kawasaki disease and multisystem inflammatory syndrome in children with COVID-19. SN Compr Clin Med. 2020;2:1-6. https://doi.org/10.1007/s42399-020-00558-9.

83. Sokolovsky S, Soni P, Hoffman T, Kahn P, Scheers-Masters J. COVID-19 associated Kawasaki-like multisystem inflammatory disease in an adult. Am J Emerg Med. 2021;39:253 e1-2. https://doi.org/10.1016/j.ajem.2020.06.053.

84. Toubiana J, Poirault C, Corsia A, Bajolle F, Fourgeaud J, Angoulvant F, et al. Kawasaki-like multisystem inflammatory syndrome in children during the covid-19 pandemic in Paris, France: prospective observational study. BMJ. 2020;369:m2094. https://doi.org/10.1136/bmj.m2094.

85. Yeo WS, Ng QX. Distinguishing between typical Kawasaki disease and multisystem inflammatory syndrome in children (MISC) associated with SARS-CoV-2. Med Hypotheses. 2020;144: 110263. https://doi.org/10.1016/j.mehy.2020.110263.

86. Yeung RS, Ferguson PJ. Is multisystem inflammatory syndrome in children on the Kawasaki syndrome spectrum? J Clin Invest. 2020;130(11):5681-4. https://doi.org/10.1172/JCI141718.

87. Zhang RL, Lo HH, Lei C, Ip N, Chen J, Law BY. Current pharmacological intervention and development of targeting IVIG resistance in Kawasaki disease. Curr Opin Pharmacol. 2020;54:7281. https://doi.org/10.1016/j.coph.2020.08.008.

88. Balgradean M, Cinteza E, Aria LA, Matei RL, Marin L, Moga L, et al. Clinical and pathogenic correlations between SARS-CoV-2 infection and hemolytic uremic syndrome in children. Maedica (Bucur). 2020;15(3):376-80. https://doi.org/10.26574/maedica. 2020.15.3.376.

89. Ahmed M. Coronavirus disease 2019: a gastroenterologist's perspective in May 2020. Gastroenterology Res. 2020;13(3):89-95. https://doi.org/10.14740/gr1292.

90. AlGhoozi DA, AlKhayyat HM. A child with Henoch-Schonlein purpura secondary to a COVID-19 infection. BMJ Case Rep. 2021;14(1). https://doi.org/10.1136/bcr-2020-239910.

91. Whittaker E, Bamford A, Kenny J, Kaforou M, Jones CE, Shah P, et al. Clinical characteristics of 58 children with a pediatric inflammatory multisystem syndrome temporally associated with SARSCoV-2. JAMA. 2020;324(3):259-69. https://doi.org/10.1001/ jama.2020.10369.

92. Cheung EW, Zachariah P, Gorelik M, Boneparth A, Kernie SG, Orange JS, et al. Multisystem inflammatory syndrome related to COVID-19 in previously healthy children and adolescents in New York City. JAMA. 2020;324(3):294-6. https://doi.org/10.1001/ jama.2020.10374.

93. Jain S, Sen S, Lakshmivenkateshiah S, Bobhate P, Venkatesh S, Udani S, et al. Multisystem inflammatory syndrome in children with COVID-19 in Mumbai. India Indian Pediatr. 2020;57(11): 1015-9.

94. Jonat B, Gorelik M, Boneparth A, Geneslaw AS, Zachariah P, Shah A, et al. Multisystem inflammatory syndrome in children associated with coronavirus disease 2019 in a Children's Hospital in New York City: Patient Characteristics and an Institutional Protocol for Evaluation, Management, and FollowUp. Pediatr Crit Care Med. 2020;22:e178-91. https://doi.org/10. 1097/PCC.0000000000002598.

95. Kaushik A, Gupta S, Sood M, Sharma S, Verma S. A systematic review of multisystem inflammatory syndrome in children associated with SARS-CoV-2 infection. Pediatr Infect Dis J. 
2020;39(11):e340-e6. https://doi.org/10.1097/INF. 0000000000002888 .

96. Kaushik S, Aydin SI, Derespina KR, Bansal PB, Kowalsky S, Trachtman R, et al. Multisystem inflammatory syndrome in children associated with severe acute respiratory syndrome coronavirus 2 infection (MIS-C): a multi-institutional study from New York City. J Pediatr. 2020;224:24-9. https://doi.org/10.1016/j. jpeds.2020.06.045.

97. Kest H, Kaushik A, DeBruin W, Colletti M, Goldberg D. Multisystem inflammatory syndrome in children (MIS-C) associated with 2019 novel coronavirus (SARS-CoV-2) infection. Case Rep Pediatr. 2020;2020:8875987-4. https://doi.org/10.1155/ 2020/8875987.

98. Krikilion J, Nuyttens L, Daelemans S, Francois K, Mauel R, De Wolf D, et al. Varying presentations of multisystem inflammatory syndrome temporarily associated with COVID-19. Case Rep Pediatr. 2020;2020:8878946-6. https://doi.org/10.1155/2020/ 8878946.

99. Mamishi S, Movahedi Z, Mohammadi M, Ziaee V, Khodabandeh M, Abdolsalehi MR, et al. Multisystem inflammatory syndrome associated with SARS-CoV-2 infection in 45 children: a first report from Iran. Epidemiol Infect. 2020;148:e196. https://doi.org/ 10.1017/S095026882000196X.

100. Morris SB, Schwartz NG, Patel P, Abbo L, Beauchamps L, Balan $\mathrm{S}$, et al. Case series of multisystem inflammatory syndrome in adults associated with SARS-CoV-2 infection - United Kingdom and United States, March-August 2020. MMWR Morb Mortal Wkly Rep. 2020;69(40):1450-6. https://doi.org/10.15585/mmwr. mm6940e1.

101. Ozsurekci Y, Gurlevik S, Kesici S, Akca UK, Oygar PD, Aykac $\mathrm{K}$, et al. Multisystem inflammatory syndrome in children during the COVID-19 pandemic in Turkey: first report from the Eastern Mediterranean. Clin Rheumatol. 2021. https://doi.org/10.1007/ s10067-021-05631-9.

102. Pereira MFB, Litvinov N, Farhat SCL, Eisencraft AP, Gibelli M, Carvalho WB, et al. Severe clinical spectrum with high mortality in pediatric patients with COVID-19 and multisystem inflammatory syndrome. Clinics (Sao Paulo). 2020;75:e2209. https://doi. org/10.6061/clinics/2020/e2209.

103. Sethuraman U, Kannikeswaran N, Ang J, Singer A, Miller J, Haddad R, et al. Multisystem inflammatory syndrome in children associated with novel coronavirus SARS-CoV-2: presentations to a pediatric emergency department in Michigan. Am J Emerg Med. 2021;39:164-7. https://doi.org/10.1016/j.ajem.2020.10.035.

104. Soma VL, Shust GF, Ratner AJ. Multisystem inflammatory syndrome in children. Curr Opin Pediatr. 2020;33:152-8. https://doi. org/10.1097/MOP.0000000000000974.

105. Torres JP, Izquierdo G, Acuna M, Pavez D, Reyes F, Fritis A, et al. Multisystem inflammatory syndrome in children (MIS-C): report of the clinical and epidemiological characteristics of cases in Santiago de Chile during the SARS-CoV-2 pandemic. Int J Infect Dis. 2020;100:75-81. https://doi.org/10.1016/j.ijid.2020. 08.062 .
106. Ramcharan T, Nolan O, Lai CY, Prabhu N, Krishnamurthy R, Richter AG, et al. Paediatric Inflammatory Multisystem Syndrome: Temporally Associated with SARS-CoV-2 (PIMSTS): Cardiac features, management and short-term outcomes at a UK Tertiary Paediatric Hospital. Pediatr Cardiol. 2020;41(7): 1391-401. https://doi.org/10.1007/s00246-020-02391-2.

107. Minocha PK, Phoon CKL, Verma S, Singh RK. Cardiac findings in pediatric patients with multisystem inflammatory syndrome in children associated With COVID-19. Clin Pediatr (Phila). 2020: 9922820961771. https://doi.org/10.1177/0009922820961771.

108. Grimaud M, Starck J, Levy M, Marais C, Chareyre J, Khraiche D, et al. Acute myocarditis and multisystem inflammatory emerging disease following SARS-CoV-2 infection in critically ill children. Ann Intensive Care. 2020;10(1):69. https://doi.org/10.1186/ s13613-020-00690-8.

109. Cao L, Zhang S, Luo X, Wang E, Bai Y, Li Z, et al. Myocardium injury biomarkers predict prognosis of critically ill coronavirus disease 2019 (COVID-19) patients. Ann Palliat Med. 2020;9(6): 4156-65. https://doi.org/10.21037/apm-20-2112.

110.• Consiglio CR, Cotugno N, Sardh F, Pou C, Amodio D, Rodriguez $\mathrm{L}$, et al. The immunology of multisystem inflammatory syndrome in children with COVID-19. Cell. 2020;183(4):968-81 e7. https:// doi.org/10.1016/j.cell.2020.09.016 This report points put to the differences between the severe COVID-19 and MIS-C.

111. Beckmann ND, Comella PH, Cheng E. Lepow L. Mouskas K, et al. Cytotoxic lymphocytes are dysregulated in multisystem inflammatory syndrome in children. medRxiv: Beckmann AG; 2020. https://doi.org/10.1101/2020.08.29.20182899.

112.• Diorio C, Henrickson SE, Vella LA, McNerney KO, Chase J, Burudpakdee C, et al. Multisystem inflammatory syndrome in children and COVID-19 are distinct presentations of SARSCoV-2. J Clin Invest. 2020;130(11):5967-75. https://doi.org/10. $1172 /$ JCI140970 The report shows distinct differences between Kawasaki and MIS-C.

113. Vella L, Giles JR, Baxter AE, Oldridge DA, Diorio C, Alanio C, et al. Deep immune profiling of MIS-C demonstrates marked but transient immune activation compared to adult and pediatric COVID-19. medRxiv. 2020. https://doi.org/10.1101/2020.09.25. 20201863.

114.• Carter MJ, Fish M, Jennings A, Doores KJ, Wellman P, Seow J, et al. Peripheral immunophenotypes in children with multisystem inflammatory syndrome associated with SARS-CoV-2 infection. Nat Med. 2020;26(11):1701-7. https://doi.org/10.1038/s41591020-1054-6 Immunophenotyping of the MIS-C patients using current technology and using patient clinical manifestations.

115. Anderson EM, Diorio C, Goodwin EC, McNerney KO, Weirick ME, Gouma S, et al. SARS-CoV-2 antibody responses in children with MIS-C and mild and severe COVID-19. medRxiv. 2020. https://doi.org/10.1101/2020.08.17.20176552.

Publisher's Note Springer Nature remains neutral with regard to jurisdictional claims in published maps and institutional affiliations. 